\title{
Breast cancer after chest irradiation for lymphoma: case report
}

\author{
Danilo Rafael da Silva Fontinele ${ }^{*} \bullet$ C, Sabas Carlos Vieira² ${ }^{\circ}$
}

\section{ABSTRACT}

Breast cancer is one of the most common diseases among women worldwide. One of the risk factors for the development of this neoplasia is previous radiotherapy on the chest wall. Breast cancer, in turn, is the main long-term concern among women treated for lymphoma with radiation on the chest wall. Thus, we present a case of breast cancer that appeared 18 years after chest radiation for the treatment of lymphoma.

KEYWORDS: breast neoplasms; lymphoma; radiotherapy.

\section{INTRODUCTION}

Breast cancer is one of the most common diseases and an important public health challenge among women worldwide. Some of the risk factors for the development of this neoplasm are, family history, reproductive factors, lifestyle, and previous radiation therapy on the chest wall, especially in young patients ${ }^{1,2}$.

On the other hand, radiotherapy is important in the treatment of lymphomas. Although the risk of recurrent lymphoma decreases in long-term survivors, the incidence of radiationinduced cancers increases with time. Breast cancer, in turn, is the main long-term concern among women who have been previously treated for lymphoma with radiation on the chest wall ${ }^{3}$.

Thus, we report a case of breast cancer that arose after chest radiation for the treatment of lymphoma.

\section{CASE REPORT}

A 43-year-old patient was diagnosed with non-special invasive carcinoma in the left breast during a routine examination by means of imaging tests (mammography, ultrasound and breast resonance). On the resonance, the tumor measured $0.7 \mathrm{~cm}$. She had a history of chest irradiation for lymphoma 18 years prior (Figure 1), with no evidence of disease activity when the breast cancer was diagnosed. We did not have access to the histological type of the lymphoma. In her family history, she has two sisters that had BRCA1 mutations; one developed breast cancer, and the other underwent prophylactic oophorectomy. The BRCA mutation test was negative for the patient. She underwent a bilateral mastectomy with preservation of the skin and the nipple-areolar complex (Figure 2). A histological examination of the surgical specimens showed no tumor on the right breast, and on the left breast, the following were identified: a non-special invasive carcinoma of $0.7 \mathrm{~cm}$ in the largest diameter, G2, negative sentinel lymph node, Luminal A (90\% estrogen receptors, progesterone receptors $90 \%$, ki-67 10\%, human epidermal growth factor type 2 receptor $2+$,

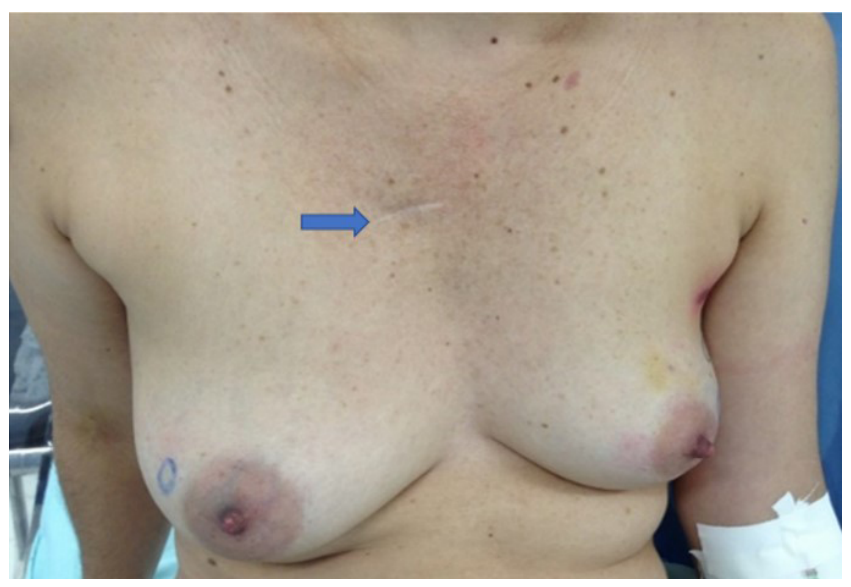

Arrow: catheter scar for lymphoma treatment 18 years earlier; circle: fibroadenoma in the right breast.

Figure 1. Scar from the catheter implantation site for chemotherapy to treat lymphoma. 
hybridization in situ negative fluorescent). The oncotype demonstrated a Recurrence Score of 9. Four months after breast surgery, she presented clinical worsening of deep endometriosis. A hysterectomy with a bilateral adnexectomy was performed using videolaparoscopy. In the 54-month follow-up (Figure 3), she did not have a recurrence of the disease and was using exemestane and zoledronic acid, and had a good quality of life. The study was approved by the Research Ethics Committee of the Universidade Federal do Piauí, number 2,948,415. Additionally, the patient signed an informed consent form.

\section{DISCUSSION}

Radiation used to treat lymphoma has the ability to cause molecular damage to human body tissues, including cell death and functional changes. The effects can be tissue reactions or stochastic effects, the highest ones indicate a higher dose of radiation to be used, and they are cumulative. Therefore, the consequences are late and may lead to the development of malignant neoplasms, especially in patients exposed to radiation before the age of ten ${ }^{4}$.

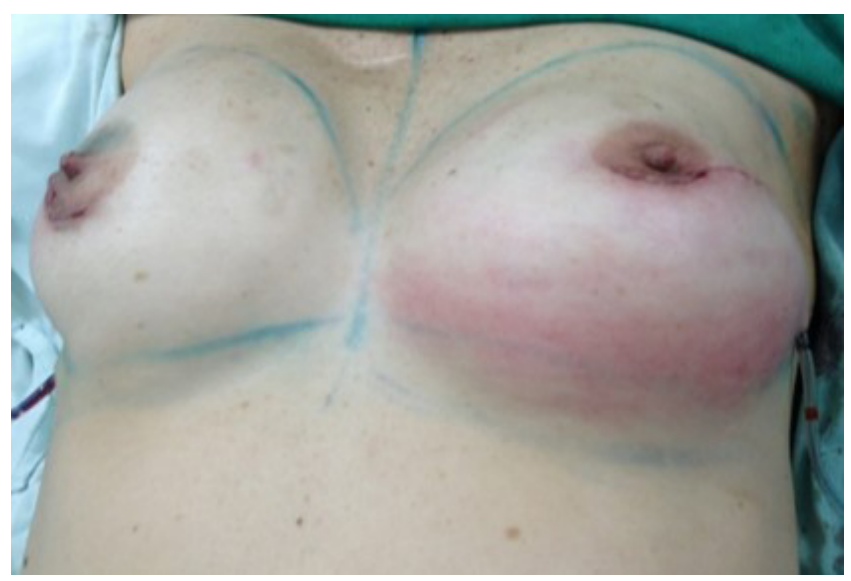

Figure 2. Result of a bilateral mastectomy with skin preservation and nipple-areolar complex, with inclusion of bilateral submuscular prosthesis and an investigation of the left sentinel lymph node.

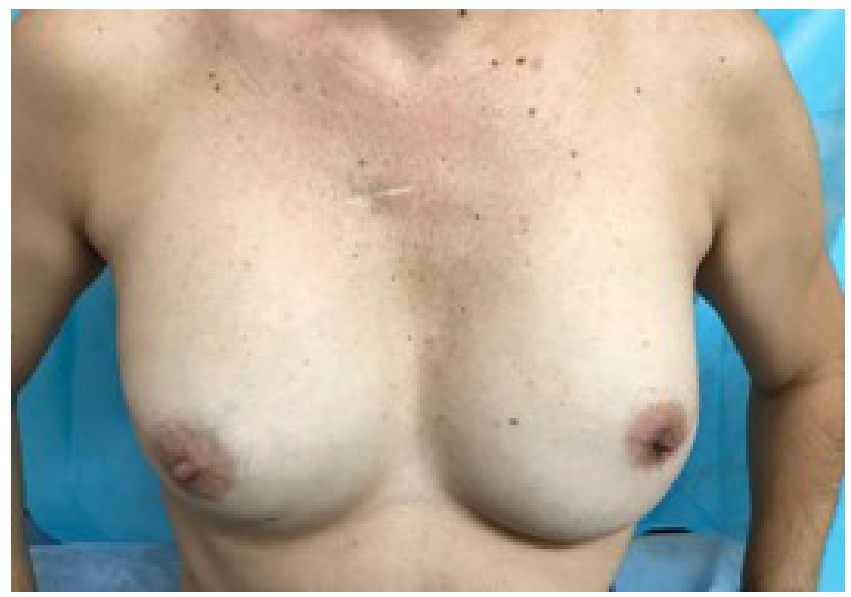

Figure 3.54 months after surgery.
The risk of developing new cancer after radiotherapy depends on the dose and location of the treatment, and there may be an additional risk of breast, thyroid, leukemia and lung cancer-6. The highest risk is found in the subgroup of patients who received treatment as young children, with a wide description of cases between 10 and 14 years old. In patients older than 35 years old who underwent treatment, there was no difference in changes in relative risks. ${ }^{5}$.In the present case, the tumor appeared 18 years after the lymphoma treatment.

Some authors recommend an evaluation of the dose-volume used in radiotherapy as a determining factor for the risk of developing a second primary cancer. However, a meta-analysis published in $2018^{7}$ failed to measure and/or associate dose-volume with variations in additional risk due to incompatibility and heterogeneity in the description of the data collected in the various studies.

In a study of the follow-up of patients after treatment for Hodgkin's lymphoma ${ }^{8}$, in a single center, the risk of developing the second cancer was $80.8 \%$. Breast cancer was the second most frequent, second only to lung cancer. In other studies, breast cancer was the most prevalent after chest wall radiotherapy for the treatment of lymphoma ${ }^{9}$.

A study published in 2005 crossed data from patients undergoing treatment for lymphoma who used radiotherapy with the use of alkylating agents ${ }^{10}$. The use of alkylating agents decreased the chance of developing a second neoplasm, whereas higher doses of radiotherapy (> 40Gy) without the use of alkylating agents represented a greater risk of developing the disease. In the case presented here, we did not have access to the chemotherapy regimen that the patient underwent for the treatment of lymphoma.

Compared to sporadic breast cancer, breast cancer after radiotherapy was more likely to be bilateral (6\%-34\%), to have negative hormone receptors (27\%-49\%), and to be high-grade (35\%). Disease-free survival has been shown to be similar to groups of patients with primary breast cancer of the same immunohistochemical profile, although comorbidities are greater in the groups of patients who received previous radiation therapy, probably due to the effects of the initial treatment ${ }^{11}$. Due to the risk of bilateral breast cancer, the recommended treatment is a bilateral mastectomy, as performed in the case analyzed in this study.

Identifying groups at risk of developing second primary cancer is crucial for strategies to be adopted, to facilitate screening and to minimize consequences. Therefore, women who received radiation in the thoracic region due to a malignant disease in childhood are recommended to keep screening for breast cancer with an annual mammography, starting at the age of 25 , or eight years after the initial radiotherapy, whichever comes first $\mathrm{t}^{12,13}$.

A systematic review published in 2010 found that, although the outcome of patients diagnosed with breast cancer after childhood radiotherapy is similar to that of patients diagnosed with breast cancer without prior radiation therapy, studies suggest specific screening strategies, as the risk determined 
by radiotherapy appears to remain stable over the years and does not reach a plateau, which keeps patients in an increasingly high risk group ${ }^{14}$.

In a systematic review, published in 2018, it is suggested that mammography and MRI screenings be performed starting at the age of 25 or after eight years of initial radiotherapy (whichever comes first) in women who received> 20 Gy in the chest wall before turning 30 years old ${ }^{10,11}$. Other authors already recommend the practice for groups that received > 10 Gy in the chest wall. Genetic tests can be considered in specific cases and are able to help identify the highest risk cases ${ }^{11}$.

\section{CONCLUSION}

Breast cancer is the main malignancy to develop after radiotherapy to treat lymphoma. Due to the cumulative factor of ionizing radiation, the risk increases after several years of treatment, especially in cases of patients who received high doses of radiation therapy. However, the data are still very heterogeneous and may be influenced by variables related to other treatment modalities. Currently, we must stratify the groups at greatest risk. Nevertheless, a model that combines the increased risk of radiation therapy with predisposing genetic factors should offer a guide towards more successful and targeted screening strategies and approaches in the future.

\section{AUTHORS' CONTRIBUTION}

D.F.: Design, data curation, formal analysis, research, methodology, project management, resources, software, validation, visualization, writing - reviewing and editing.

S.V.: Design, data curation, formal analysis, acquisition of funding, research, methodology, project management, supervision, validation, visualization, writing - reviewing and editing.

\section{REFERENCES}

1. Sun YS, Zhao Z, Yang ZN, Xu F, Lu HJ, Zhu ZY, et al. Risk Factors and Preventions of Breast Cancer. Int J Biol Sci. 2017;13(11):1387-97. https://dx.doi. org/10.7150\%2Fijbs.21635

2. Rojas K, Stuckey A. Breast Cancer Epidemiology and Risk Factors. Clin Obstet Gynecol. 2016;59(4):651-72. https://doi. org/10.1097/grf.0000000000000239

3. Wahner-Roedler DL, Petersen IA. Risk of Breast Cancer and Breast Cancer Characteristics in Women After Treatment for Hodgkin Lymphoma. Drugs Today (Barc). 2004;40(10):865-79. https://doi.org/10.1358/ dot.2004.40.10.863746

4. Okumo E. Efeitos biológicos das radiações ionizantes: acidente radiológico de Goiânia. Estud Av. 2013;27(77):185-200. https:// doi.org/10.1590/S0103-40142013000100014

5. Willett W, Tamimi R, Hankinson S, Hunter D, Colditz G, Nongenetic factors in the causation of breast cancer. In: Harris JR, Lippman ME, Morrow M, Osborne CK, editores. Diseases of the breast. $4^{\mathrm{a}}$ ed. Philadelphia: Lippincott/Wolters Kluwer Health; 2009. p. 248-275.

6. Hancock S, Tucker MA, Hoppe RT. Breast cancer after treatment of Hodgkin's disease. J Natl Cancer Inst. 1993;85(1):25-31. https://doi.org/10.1093/jnci/85.1.25

7. Journy N, Mansouri I, Allodji RS, Demoor-Goldschmidt C, Ghazi D, Haddy N, et al. Volume Effects of radiotherapy on the risk of second primary cancers: A systematic review of clinical and epidemiological studies. Radiother Oncol. 2019;131:150-9. https://doi.org/10.1016/j. radonc.2018.09.017
8. Petrakova K, Vyskocil J, Grell P, Majek O, Soumarova R, Novak J, et al. Second cancers in Hodgkin's lymphoma long-term survivals: A 60-year single institutional experience with reallife cohort of 871 patients. Int J Clin Pract. 2018;72(9):e13285. https://doi.org/10.1111/ijcp.13235

9. Zedníková I, Safránek J, Hlaváčková M, Hes O, Svoboda T. Sarcoma of the Chest Wall After Radiotherapy for Breast Carcinoma - A Case Report. Rozhl Chir. 2014;93(7):396-400.

10. Travis LB, Hill D, Dores GM, Gospodarowicz M, van Leeuwen FE, Holawaty E, et al. Cumulative Absolute Breast Cancer Risk for Young Women Treated for Hodgkin Lymphoma. J Natl Cancer Inst. 2005;97(19):1428-37. https://doi.org/10.1093/jnci/dji290

11. Derman YE. Clinical Practice Recommendations based on an updated review of breast cancer risk among women treated for childhood cancer. J Pediatr Oncol Nurs. 2018;35(1):65-78. https://doi.org/10.1177/1043454217727515

12. Daly MB, Pilarski R, Berry M, Buys SS, Farmer M, Friedman S, et al. National Comprehensive Cancer Network (NCCN): Genetic/ Familial High-Risk Assessment: Breast and Ovarian, Version 2.2017. 2017;15(1):9-20. https://doi.org/10.6004/jnccn.2017.0003

13. Oeffinger KC, Ford JS, Moskowitz CS, Diller LR, Hudson MM, Chou JF, et al. Breast Cancer Surveillance practices among women previously treated with chest radiation for a childhood cancer. JAMA. 2009;301(4):404-14. https://doi.org/10.1001/jama.2008.1039

14. Henderson TO, Amsterdam A, Bhatia S, Hudson MM, Meadows AT,NegliaJP, etal.Systematic review:surveillanceforbreastcancer in women treated with chest radiation for childhood, adolescent, or young adult cancer. Ann Intern Med. 2010;152(7):444-55. https://doi.org/10.7326/0003-4819-152-7-201004060-00009 